\title{
Relationship between circulating anti-Müllerian hormone (AMH) and superovulatory response of high-producing dairy cows
}

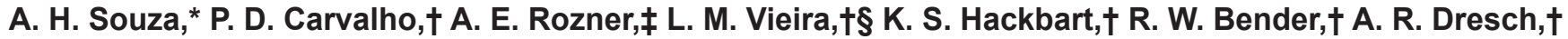 \\ J. P. Verstegen, $\ddagger$ R. D. Shaver, $†$ and M. C. Wiltbank ${ }^{1}$ \\ *University of California Cooperative Extension, Tulare 93274 \\ †Department of Dairy Science, University of Wisconsin-Madison, Madison 53706 \\ $\ddagger$ MofA Global, International Center for Biotechnology, Mt. Horeb, WI 53572 \\ §Department of Animal Sciences, University of Sao Paulo-VRA, 05508 São Paulo, SP Brazil
}

\section{ABSTRACT}

The main objective of this study was to evaluate the relationship between circulating anti-Müllerian hormone $(\mathrm{AMH})$ and superovulatory response of dairy cows. Holstein cows $(\mathrm{n}=72)$ were milked twice daily and housed and fed individually in tiestalls. All animals were synchronized and flushed at $70 \pm 3 \mathrm{~d}$ in milk (DIM), near peak production $(39.6 \mathrm{~kg} / \mathrm{d})$. Blood samples for $\mathrm{AMH}$ analysis were collected at 3 different stages of a synchronized estrous cycle [at a random stage (40 \pm 3 DIM), proestrus (50 \pm 3 DIM), and diestrus (57 \pm 3 DIM)]. Body weights were measured weekly from calving until embryo collection. Statistical analyses were performed with Proc CORR and Proc GLIMMIX of SAS (SAS Institute Inc., Cary, NC). The $3 \mathrm{AMH}$ samples from individual cows were correlated and not influenced by day of cycle. Surprisingly, AMH tended to be negatively correlated with body weight loss from calving to embryo collection $(\mathrm{r}=-0.22)$. More importantly, average AMH was highly associated $(\mathrm{r}=0.65)$ with superovulation response (number of corpora lutea on the day of the flush, CLN), total structures collected $(\mathrm{r}=0.48)$, and total transferable embryos $(\mathrm{r}=0.37)$, but not percentage of fertilized embryos $(\mathrm{r}=-0.20)$ or degenerate embryos $(r=0.02)$. When cows were classified into quartiles (Q) of circulating AMH (Q1 = 0.01 to $82.6 \mathrm{pg} / \mathrm{mL}$; $\mathrm{Q} 2=91.1$ to $132.5 \mathrm{pg} / \mathrm{mL} ; \mathrm{Q} 3=$ 135.3 to $183.8 \mathrm{pg} / \mathrm{mL}$; $44=184.4$ to $374.3 \mathrm{pg} / \mathrm{mL}$ ), we observed a $>2$-fold difference between first and fourth $\mathrm{AMH}$ quartiles in superovulation response (CLN: Q1 $=12.0 \pm 1.5 ; \mathrm{Q} 2=14.7 \pm 2.0 ; \mathrm{Q} 3=17.2 \pm 1.2 ; \mathrm{Q} 4$ $=25.6 \pm 1.5)$ and embryo production. In conclusion, circulating AMH concentration was strongly associated with superovulation response, and evaluation of $\mathrm{AMH}$ could be used to identify cows with greater responses to

Received March 29, 2014.

Accepted September 24, 2014.

${ }^{1}$ Corresponding author: wiltbank@wisc.edu superstimulation and thus improve efficiency of superovulation programs in dairy cows.

Key words: superovulation, embryo transfer, dairy cow, anti-Müllerian hormone

\section{INTRODUCTION}

Recent advances in bovine biotechnology, such as commercially available genomics testing, have allowed for the identification of animals with superior genetics. However, cost-efficient propagation of these superior genetics has been hampered by high variability between animals in response to embryo production techniques, such as superovulation. For example, $30 \%$ of the cows are responsible for $70 \%$ of the embryos produced during superovulation programs (Bó and Mapletoft, 2014; Hasler, 2014). More-accurate identification of cows with greater embryo production potential could allow for more efficient production of in vitro and in vivo bovine embryos from cows with superior genetics.

Ultrasound determination of antral follicle count has been shown to be correlated with subsequent response to superstimulation in cattle (Singh et al., 2004; Ireland et al., 2007). However, under practical conditions, substantial variation can exist in experience of ultrasound operators, characteristics of ultrasound machines, operator-defined criteria for counting antral follicles, and stage of the follicular wave at time of evaluation (Singh et al., 2004; Burns et al., 2005; Monniaux et al., 2010). A combination of these variables may make it more difficult to reliably select the cows with the greatest capacity for production of embryos under field conditions. Laboratory methods that reliably predict antral follicle numbers and response to superovulation could have substantial value for selection of cows for use in biotechnology protocols or for genomic selection of cows with greater reproductive capacity. In humans, circulating anti-Müllerian hormone (AMH) concentrations have been found to be the most informative serum marker for ovarian follicle reserve, largely replac- 
ing other serum markers such as basal FSH testing (Fanchin et al., 2003; Broekmans et al., 2006; Toner and Seifer, 2013). Information is also accumulating in cattle that measurement of circulating AMH concentrations may be the most reliable method for predicting antral follicle numbers (Ireland et al., 2011; Monniaux et al., 2013; Batista et al., 2014).

Anti-Müllerian hormone is a $140-\mathrm{kDa}$ glycoprotein that is a member of the transforming growth factor $\beta$ (TGF $\beta$ ) gene/protein family (Knight and Glister, 2006). Anti-Müllerian hormone is exclusively expressed in the gonads, within Sertoli cells of the male and granulosa cells of the female (Monniaux et al., 2013). The physiological function of AMH in adult females is still an area of active research; however, AMH has been shown to modulate early follicular growth and may thereby inhibit excessive number of follicles from entering the growing follicle pool, preventing premature depletion of the ovarian follicle reserve (Durlinger et al., 1999, 2002; Monniaux et al., 2012).

Studies in cattle have confirmed the localization of AMH expression to granulosa cells of small antral growing follicles (Rico et al., 2011) and have defined important aspects of the hormonal regulation of $\mathrm{AMH}$ expression and secretion from granulosa cells (Rico et al., 2011; Scheetz et al., 2012; Monniaux et al., 2013). It has been demonstrated in cattle, similar to humans (Nelson, 2013), that circulating AMH concentration is a reliable endocrine marker for the size of the antral follicle population (Ireland et al., 2011; Rico et al., 2011; Monniaux et al., 2012). Studies in the bovine have also evaluated $\mathrm{AMH}$ concentrations in peripubertal calves, during the periparturient period, and during the normal bovine estrous cycle (Monniaux et al., 2013). In some studies (Ireland et al., 2011; Rico et al., 2011; Monniaux et al., 2013), small but significant variations in $\mathrm{AMH}$ concentrations have been detected under different physiological conditions; however, major variations in AMH concentrations are observed between individuals, demonstrating that cows with a greater antral follicle population have much higher AMH concentrations than cows with a smaller antral follicle population. Thus, the basic studies provide a strong foundation for studies evaluating the practical use of AMH measurements for reproductive biotechnologies in cattle.

Results from the limited number of studies investigating the relationship between circulating $\mathrm{AMH}$ and in vivo embryo production following superovulation of dairy cattle have been encouraging. An early experiment (Rico et al., 2009) evaluated 18 Holstein cattle and reported a strong correlation between plasma AMH concentrations and numbers of large follicles after superstimulation $(\mathrm{r}=0.83)$ and number of CL after superovulation $(\mathrm{r}=0.64)$; however, relationships to embryo numbers were not reported. The largest study (Monniaux et al., 2010) used 45 crossbred Holstein $\times$ Normande dairy cows and compared plasma AMH (60-90 DIM) with embryo production during a total of 240 superovulation protocols over a 4-yr time period. In that study, no information was provided on superovulatory response but plasma AMH concentrations were correlated with average numbers of embryos collected per cow $(r=0.49)$ and average number of transferable embryos per donor cow $(r=0.32)$. Two subsequent studies by this same research group (Rico et al., 2012), in 64 superstimulated, nonlactating Holstein cows, found a high correlation of circulating AMH concentrations to number of large follicles following superstimulation $(\mathrm{r}=0.56)$ and to corpus luteum $(\mathbf{C L})$ numbers after superovulation $(\mathrm{r}=0.43)$, although embryo production was not reported. Finally, a study in 34 Japanese Black cows (Hirayama et al., 2012) reported a correlation between $\mathrm{AMH}$ concentrations and numbers of transferable embryos $(\mathrm{r}=0.39)$. Thus, previous studies are consistent in showing that circulating AMH is a good predictor of superstimulation, superovulation, and embryo production, although only one of the studies combined all 3 responses. In addition, the largest studies were done in nonlactating (Rico et al., 2012), crossbred (Monniaux et al., 2010), or beef (Hirayama et al., 2012) cattle. Given the potential importance of $\mathrm{AMH}$ as a predictor of reproductive capacity, further studies are needed on the repeatability of this assay during the estrous cycle and predictability of this assay for superovulatory and embryo production responses in lactating Holstein cattle.

Thus, the objective of this study was to investigate whether circulating AMH could be used as a predictor for superovulation response and embryo production in synchronized, high-producing, lactating Holstein dairy cattle. Concentrations of AMH were evaluated at 3 different times in all cows to determine within-cow repeatability of AMH measurements, as well as any effects of estrous cycle stage on AMH concentrations. Our main hypothesis was that cows with greater circulating $\mathrm{AMH}$ would have increased numbers of ovulations after superstimulation with FSH and increased yield of transferable embryos in response to the superovulation protocol.

\section{MATERIALS AND METHODS}

\section{Animal Housing and Diets}

All procedures were approved by the Animal Care Committee of the College of Agriculture and Life Sciences, University of Wisconsin-Madison. Seventy-two lactating Holstein cows (primiparous $=28$, multiparous 
$=44)$ were housed at US Dairy Forage Research Center (Madison, WI) in individual tiestalls from calving to 70 \pm 3 DIM. Cows were fed individually ad libitum a TMR once a day, consisting of corn silage $(9.98 \mathrm{~kg}$ of $\mathrm{DM} / \mathrm{d})$, alfalfa silage $(5.44 \mathrm{~kg}$ of $\mathrm{DM} / \mathrm{d})$, and grass hay $(0.9$ $\mathrm{kg}$ of $\mathrm{DM} / \mathrm{d}$ ) as forage; and a concentrate containing roasted whole soybean $(2.13 \mathrm{~kg}$ of $\mathrm{DM} / \mathrm{d})$, high-moisture corn $(4.54 \mathrm{~kg}$ of $\mathrm{DM} / \mathrm{d})$, and canola meal $(1.0 \mathrm{~kg}$ of $\mathrm{DM} / \mathrm{d})$, supplemented with vitamins and minerals, and balanced to meet or exceed minimum requirements for lactating dairy cows (Cornell Net Carbohydrate and Protein System-6.1; http://cncps.cornell.edu/). Body weights were measured weekly from day of calving until embryo collection.

\section{Superovulation Protocol}

Cows were superstimulated with a modified 5-d Double Ovsynch protocol that began at $40 \pm 3$ DIM as previously described (Carvalho et al., 2014). The superovulation was done with prostaglandin $\mathrm{F}_{2 \alpha}$ (Estrumate, $500 \mu \mathrm{g}$ of cloprostenol sodium/dose; Schering-Plough Animal Health, Union, NJ), GnRH (gonadorelin diacetate tetrahydrate; $100 \mu \mathrm{g}$; Cystorelin; Merial, Duluth, GA), FSH (400 mg, Folltropin-V; Bioniche Life Sciences, Belleville, ON, Canada), and intravaginal progesterone (P4) implants (Eazi-Breed CIDR; containing $1.38 \mathrm{~g}$ of P4; Pfizer Animal Health, New York, NY). Briefly (Figure 1), cows were presynchronized using an Ovsynch protocol with the addition of a CIDR between first $\mathrm{GnRH}$ and $\mathrm{PGF}_{2 \alpha}$ (d 0, GnRH plus CIDR insert; d 7, $\mathrm{PGF}_{2 \alpha}$ and CIDR removal; d 9, GnRH). Seven days after the last $\mathrm{GnRH}$ of the presynchronization period, all cows had follicles $>5 \mathrm{~mm}$ ablated by ultrasoundguided aspiration (Aloka 900 equipped with a $13-\mathrm{MHz}$ convex-array transducer; Aloka America, Wallingford, CT) as previously described (Bergfelt et al., 1994). Approximately $36 \mathrm{~h}$ after follicle ablation, a new CIDR was inserted and 8 decreasing FSH treatments were performed at 12-h intervals $(80 \mathrm{mg}$ a.m., $80 \mathrm{mg}$ p.m., $60 \mathrm{mg}$ a.m., $60 \mathrm{mg}$ p.m., $40 \mathrm{mg}$ a.m., $40 \mathrm{mg}$ p.m., 20 mg a.m., $20 \mathrm{mg}$ p.m.), in a total FSH dose of $400 \mathrm{mg} /$ cow. Treatment with $\mathrm{PGF}_{2 \alpha}$ was done at the fifth and seventh FSH treatments, and the CIDR was removed at the time of the last FSH. Twenty-four hours after the last FSH and CIDR removal, ovulation was induced with GnRH (Figure 1). All cows were inseminated by 1 of 2 technicians (P. D. Carvalho and A. H. Souza). Cows were inseminated twice at 12 and $24 \mathrm{~h}$ after $\mathrm{GnRH}$ with semen from the same sire and by the same technician, both equally distributed between parity groups. Nonsexed frozen semen $\left(15 \times 10^{6}\right.$ sperm/straw $)$ was used in all breeding procedures. Semen from 2 Holstein sires with high genetic merit, proven outstanding field fertility (sire conception rate USDA scores $\geq 1.5$ ), and produced from a single ejaculate per sire were used. Sperm motility (sire $1=53 \%$ and sire $2=56 \%$ at 0 h) was done objectively by using a computer-assisted semen analyzer (CEROS, Hamilton Thorne, Beverly, MA). Sperm abnormalities (sire $1=9 \%$ and sire $2=$ $14 \%$ ) and intact acrosome (sire $1=61 \%$ and sire 2 $=56 \%$ ) were evaluated under differential interference contrast (DIC) optics $(600 \times)$.

\section{Embryo Collection and Evaluation}

All cows had embryo recovery performed by 1 of 2 technicians (P. D. Carvalho and A. H. Souza). Seven days after GnRH, CL structures from both ovaries were counted by ultrasound (Aloka 900 equipped with a $13-\mathrm{MHz}$ linear-array transducer) to estimate superovulation response to the protocol. Shortly after the ovarian ultrasound evaluation, embryos were recovered using a previously described technique (Sartori et al., 2003). Lidocaine spinal anesthesia was used (lidocaine hydrochloride injectable $2 \%, 5 \mathrm{~mL} /$ dose; Phoenix Pharmaceutical Inc., St. Joseph, MO). Embryo filters (MiniFlush Embryo System), y-tubing (Y-Junction Tubing),

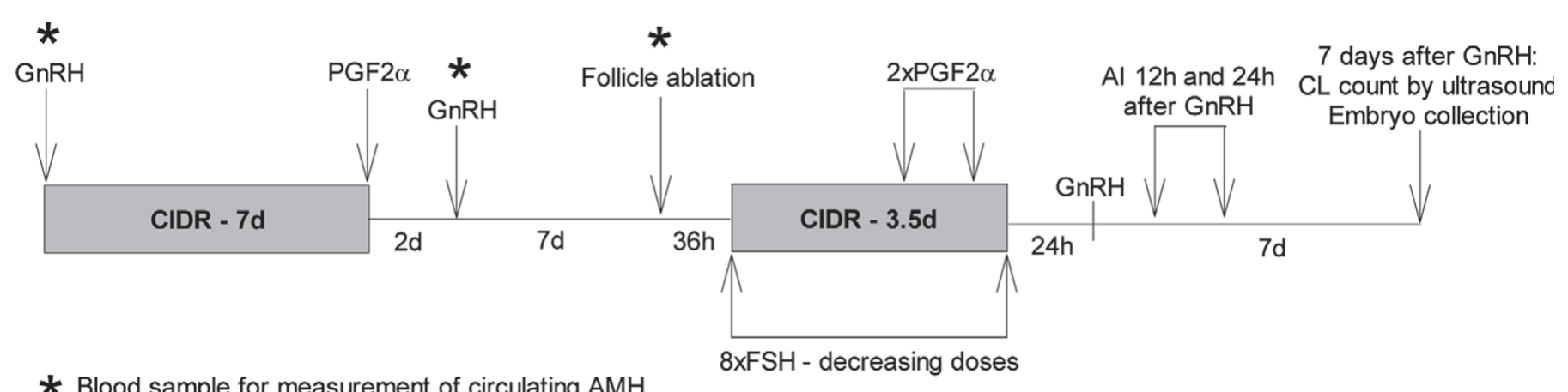

Figure 1. Schematic view of the superovulatory protocol used in this study with timing of blood sample collection for anti-Müllerian hormone $(\mathrm{AMH})$ measurements shown. CIDR = controlled internal drug-releasing insert (intravaginal progesterone implant); CL = corpus luteum. 
catheters (Silicon ET catheter CH16/CH18, 2-way Foley, 30-mL balloon), medium for embryo recovery (BoviPro Recovery Medium with PVA, 2L), holding medium (BoviPro Holding Medium, with BSA), ethylene glycol (BoviPro Ethylene Glycol with Sucrose), embryo straws (MiniStraw, $0.25 \mathrm{~mL}$ ) and plugs were from MofA Global (Verona, WI). Structures were collected onto an embryo filter, immediately washed into a Petri dish, searched under a stereo microscope, and classified for quality as 1 (excellent or good), 2 (fair), 3 (poor), or 4 (dead or degenerating) using International Embryo Transfer Society criteria (IETS, 2010) by a single technician (K. S. Hackbart).

\section{Analyses of AMH and P4}

For measurements of AMH concentrations, blood samples were collected at 3 different stages of a synchronized estrous cycle: at a random stage (40 \pm 3 DIM), proestrus (50 $\pm 3 \mathrm{DIM})$, or diestrus ( $57 \pm 3 \mathrm{DIM})$, as indicated in Figure 1. Stages were chosen to vary in hormonal concentrations, stage of follicular wave, and DIM to evaluate repeatability within a cow during different physiological conditions and to test whether physiological condition altered AMH concentration in any systematic way. Blood samples $(\sim 8 \mathrm{~mL})$ were collected into evacuated collection tubes containing EDTA (Becton Dickinson, Franklin Lakes, NJ) by puncture of the coccygeal vein or artery before the administration of each GnRH injection of the presynchronization and just before follicular ablation. Blood samples were immediately centrifuged after collection at $3,000 \times g$ for $20 \mathrm{~min}$. Plasma samples were then stored at $-20^{\circ} \mathrm{C}$ until assayed for AMH and P4. Minimum time between blood collection and freezing of plasma samples is critical for consistent circulating AMH analysis, as previously reported (Rico et al., 2012); AMH was analyzed by MofA Global using a bovine AMH ELISA (MofA Global). Analysis of P4 was done with the Coat-aCount RIA (Diagnostic Products, Los Angeles, CA) as previously described by Garbarino et al. (2004). The assay had a sensitivity of $0.04 \mathrm{pg} / \mathrm{mL}$ and coefficient of variation of $2.2 \%$.

\section{Statistical Analysis}

Animals with 3 or more CL at the time of embryo collection, determined by transrectal ultrasonography, were considered to have responded to the superovulatory treatment $(\mathrm{n}=71$ out of 72 cows). All cows underwent the embryo collection procedures and were included in the analysis, including the one cow with only 2 ovulations. The percentage of fertilized structures was calculated by dividing the total number of cleaved structures by the total number of structures; percentage freezable embryos was calculated by dividing total number of embryos grades 1 and 2 by the total number of structures; percentage transferable embryos was calculated by dividing the total number of embryos grades 1,2, and 3 by the total number of structures; and percentage of degenerated embryos was calculated by dividing the total number of degenerated embryos by the total number of structures. The percentage of degenerated embryos of the fertilized embryos was calculated by dividing the number of degenerated embryos by the total number of fertilized structures. Statistical analyses were performed using SAS computational software, version 9.3 of SAS for Windows (SAS Institute, 2011) and SigmaPlot version 12.5 (Systat Software Inc., San Jose, CA). Repeatability (range 0 to $1 ; 1=$ perfect) is defined as the proportion of total variance attributed to animal and was calculated as previously described (Boni et al., 1997). Variance components for the repeatability analysis were estimated with PROC GLIMMIX and the model included only the random effect of cow and the fixed effect of blood sampling period. The GLIMMIX procedure was also used to compare embryo characteristics using cow as the experimental unit. The final logistic regression models included $\mathrm{AMH}$, parity, and meaningful one-way interactions, with cow used as random effect. The type of distribution (Poisson, binomial, T-distribution) of the response variable was included in the GLIMMIX model statement. Bonferroni correction was employed when performing multiple comparisons among AMH quartiles. Correlation analyses were performed with the CORR procedure in SAS. Cut-off points were calculated using the receiver operating characteristics (ROC) curve analysis feature in SigmaPlot. All values are expressed as least squares means \pm SEM. Statistical differences were considered significant for $P<0.05$ and as a tendency for $P<0.10$.

\section{RESULTS}

\section{AMH Repeatability}

Circulating AMH was not affected by phase of the estrous cycle $(P=0.57)$, as follows: random (DIM $=40$ $\pm 3)=133.2 \pm 10.6 \mathrm{pg} / \mathrm{mL}$; proestrus $(\mathrm{DIM}=50 \pm 3)$ $=132.7 \pm 9.7 \mathrm{pg} / \mathrm{mL}$; diestrus $(\mathrm{DIM}=57 \pm 3)=150.9$ $\pm 10.6 \mathrm{pg} / \mathrm{mL}$. In addition, we detected strong positive correlations (Figure 2) among the AMH measurements done on individual cows at different phases of the estrous cycles (random $\times$ proestrus: $\mathrm{r}=0.77, P<$ 0.01 ; random $\times$ diestrus: $\mathrm{r}=0.76, P<0.01$; proestrus $\times$ diestrus: $\mathrm{r}=0.79, P<0.01)$. Most measurements were found to be close to the predicted line of unity between each of the assays (Figure 2). Some samples 
that gave a value of zero in one of the assays were found to have higher values in a subsequent assay; however, cows with high AMH values had consistently elevated $\mathrm{AMH}$ in all assays. A further analysis was performed to evaluate the within-cow repeatability of circulating $\mathrm{AMH}$ between assays. Repeatability was found to be 0.91 on a scale of 0 (poor) to 1 (perfect). To determine a final AMH score for each individual cow, the average AMH concentration from the 3 samples was calculated. The average circulating AMH was not significantly correlated with parity number $(\mathrm{r}=0.14 ; P=0.25)$ or milk production level $(\mathrm{r}=0.06 ; P=0.59)$. However, $\mathrm{AMH}$ tended to be negatively correlated $(\mathrm{r}=-0.22 ; P=$ 0.07 ) with percentage of total BW loss between calving and embryo collection at $\sim 70$ DIM.

\section{Relationship Between AMH and Superovulatory Responses}

Average circulating $\mathrm{AMH}$ concentrations for each individual cow were correlated $(\mathrm{r}=0.65 ; P<0.01)$ with superovulation response (number of CL on the day of the flush), total structures collected $(\mathrm{r}=0.50$; $P<0.01)$, and total transferable embryos $(\mathrm{r}=0.28$; $P<0.02$ ), but not with percentage of structures that were fertilized $(\mathrm{r}=-0.16 ; P=0.18)$ or percentage of structures that were degenerate embryos $(\mathrm{r}=-0.10$; $P=0.43$ ). Figure 3 shows a scatterplot of individual superovulatory responses and circulating $\mathrm{AMH}$ for the 2 parity groups (primiparous: $\mathrm{r}=0.67 ; P<0.01$; multiparous: $\mathrm{r}=0.63 ; P<0.01)$. As illustrated in Figure 3 , although there seemed to be more multiparous cows with high AMH concentrations, the slope of the line and the correlation between AMH and CL number were very consistent between the 2 parity groups.

When cows were classified into quartiles of circulating $\mathrm{AMH}(\mathrm{Q} 1=0.01$ to $82.6 \mathrm{pg} / \mathrm{mL} ; \mathrm{Q} 2=91.1$ to $132.5 \mathrm{pg} / \mathrm{mL}$; $\mathrm{Q} 3=135.3$ to $183.8 \mathrm{pg} / \mathrm{mL}$; $4=184.4$ to $374.3 \mathrm{pg} / \mathrm{mL}$ ), we detected a remarkable difference $(P<0.01)$ among AMH quartiles in superovulatory responses (Table 1 ). There was a $>5$-fold difference between AMH concentrations in Q1 $(44.9 \mathrm{pg} / \mathrm{mL})$ and Q4 $(243.1 \mathrm{pg} / \mathrm{mL})$ and a $>2$-fold difference $(P<0.01)$ in CL numbers between Q1 (12.0) and Q4 (25.6). In addition, although percentage recovery was not different between the quartiles, the total number of ova or embryos recovered was almost 3-fold greater in Q4 (14.0) compared with Q1 (5.0). Similarly, the numbers of fertilized structures $(P=0.02)$, transferable embryos $(P$ $=0.05)$, and freezable embryos $(P=0.06)$ were greater in Q4 than in Q1, with Q2 and Q3 being intermediate. However, AMH quartile had no effect on percentage of structures that were fertilized, transferable, or freezable. A ROC curve analysis was done to determine the circulating AMH concentration that could be used to select cows that produced more than 15 CL (Figure 4). The selected cut-off point was $123.5 \mathrm{pg} / \mathrm{mL}$ (ROC curve area $=0.80, P<0.01)$.

\section{DISCUSSION}

A valid assessment of the hypothesis that AMH concentrations are predictive of superovulatory response necessitates a standardized, consistent superovulation protocol and a validated, repeatable AMH assay. For the superovulation protocol, we used follicular aspiration to synchronize emergence of the follicular wave in all cows, based on previous studies showing that, although it is not practical in many field situations, it is arguably the most effective method for precisely synchronizing a follicular wave before superovulation (Bergfelt et al., 1994, 1997; Bó et al., 2002). We used the same dose (400 $\mathrm{mg}$ ) and preparation of FSH (low LH content) for all cows to standardize superstimulation. In addition, we tried to ensure that circulating P4 concentrations were high during superstimulation by having an older CL plus a CIDR present during the superstimulation, based on previous results (Rivera et al., 2011). Overall, only 1 cow (1.4\%) did not respond to the superovulation treatments ( $>2$ ovulations). The cows averaged 17.4 ovulations per cow with a fertilization rate $>75 \%$. All of these measures indicated that the superovulatory methods used in this protocol allowed us to precisely compare superovulation to $\mathrm{AMH}$.

The AMH assay used in this study was a commercially available assay. As reported in many other studies (Ireland et al., 2011; Rico et al., 2011; Monniaux et al., 2013), the variation between individuals was substantial, ranging from 0 (below the detection of the assay) to almost $400 \mathrm{pg} / \mathrm{mL}$. We analyzed AMH at 3 different times to determine the repeatability of the AMH value in individual cows. The within-cow repeatability was found to be 0.91 and, in general, one assay provided very similar information to every other assay and to the average value for the 3 assays. This indicates that a single evaluation of AMH should provide sufficient information to establish a reasonable estimate of ovarian reserve, although it may be prudent to reexamine cows that have a value of zero in an initial assay. The high repeatability of AMH measurements across different phases of the estrous cycle, DIM, levels of milk production, and parities, as found in this study and in other studies (Ireland et al., 2011; Monniaux et al., 2013), make AMH determinations particularly useful as a clinical diagnostic (Broekmans et al., 2006). Previous studies have detected an effect of age on antral follicle count in beef heifers (Cushman et al., 2009) and dairy cows (Mossa et al., 2012). In beef heifers, the effect of 

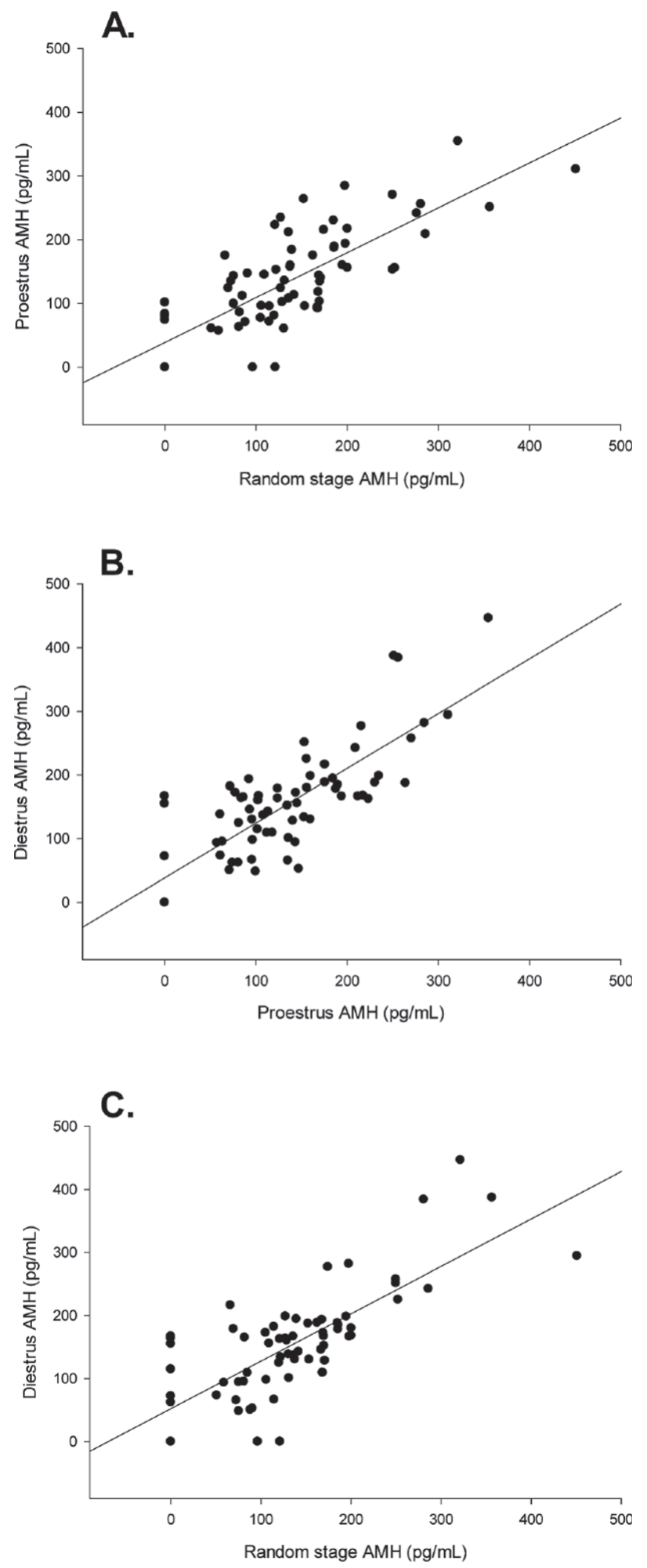

Figure 2. Comparisons between anti-Müllerian hormone (AMH) measurements done for individual cows on different times of the estrous cycle. (A) Measurement of AMH at a random stage of the cycle $(\mathrm{DIM}=40 \pm 3)$ versus $\mathrm{AMH}$ in proestrus $(\mathrm{DIM}=50 \pm 3)(\mathrm{r}=0.77, P$ $<0.01$ ); (B) measurement of AMH in proestrus versus diestrus (DIM $=57 \pm 3)(\mathrm{r}=0.79, P<0.01) ;(\mathrm{C})$ measurement of $\mathrm{AMH}$ at random stage versus diestrus $(\mathrm{r}=0.76, P<0.01)$. age was quadratic, with antral follicle counts increasing until $5 \mathrm{yr}$ of age and then declining (Cushman et al., 2009). Although our study did not detect this effect (data not shown), our cows were mostly younger (first and second lactation); therefore, more comprehensive studies of age and circulating AMH are warranted. Nevertheless, these results indicate that a single threshold for circulating AMH can be used to select donor cows regardless of when blood samples are collected in relation to follicular emergence, stage of lactation, or milk production. This represents an important practical advantage for AMH testing to predict follicular reserve and superovulatory capability and will facilitate field implementation of this technology.

In relation to our primary hypothesis and consistent with other results, circulating AMH concentrations were impressively accurate in predicting superovulatory response in terms of CL numbers and number of embryos produced by a cow in response to a standardized superovulation protocol. Both primiparous and multiparous cows demonstrated correlation coefficients between AMH and CL numbers of above $65 \%$. These results are consistent with previous studies measuring $\mathrm{AMH}$ and superovulatory response in both cattle and women (Hehenkamp et al., 2006; Monniaux et al., 2012; Rico et al., 2012). Our cut-off point for cows producing $>15 \mathrm{CL}$ and $>10$ embryos was slightly higher than those reported previously (Rico et al., 2012). For example, Rico et al. (2012) showed an AMH cut-off point of $87 \mathrm{pg} / \mathrm{mL}$ for identifying cows that produced $<15$ large follicles near the time of estrus. Differences in cut-off points between the current trial and previous studies might be related to several factors, including differing measures of superovulatory response (large follicle count near estrus; Rico et al., 2012 versus count of ovulated CL structures on the day of embryo collection in our study), different AMH assays, and different methods used to collect plasma (EDTA vs. heparin) as previously described (Rico et al., 2012). For instance, Rico et al. (2012) observed that AMH measured in frozen plasma maintained with EDTA was 1.5 times higher than if the same plasma samples were maintained with heparin. Thus, application of the 1.5 correction factor to their reported cut-off values of $87 \mathrm{pg} /$ $\mathrm{mL}$ using heparinized plasma produces a surprisingly similar value $(\sim 130 \mathrm{pg} / \mathrm{mL})$ to that calculated in our study using ROC curve analysis of samples utilizing plasma with EDTA $(124 \mathrm{pg} / \mathrm{mL})$. Based on the compatibility of these 2 studies, it is reasonable to propose that cows with circulating AMH concentrations below $\sim 90 \mathrm{pg} / \mathrm{mL}$ for heparinized plasma or $\sim 130 \mathrm{pg} / \mathrm{mL}$ for plasma collected with EDTA should be predictive of cows that would be poor responders to superovulation. In a previous study using ultrasound to determine an- 
Table 1. Superovulatory response and embryo characteristics of lactating Holstein cows divided by quartiles of circulating anti-Müllerian hormone $(\mathrm{AMH})$

\begin{tabular}{|c|c|c|c|c|c|}
\hline \multirow[b]{2}{*}{ Endpoint } & \multicolumn{4}{|c|}{$\mathrm{AMH}_{\text {quartile }}{ }^{1}$} & \multirow[b]{2}{*}{$P$-value } \\
\hline & Q1 & Q2 & Q3 & Q4 & \\
\hline Corpora lutea (no.) & $12.0 \pm 1.5^{\mathrm{a}}$ & $14.7 \pm 2.0^{\mathrm{ab}}$ & $17.2 \pm 1.2^{\mathrm{b}}$ & $25.6 \pm 2.5^{\mathrm{c}}$ & $<0.01$ \\
\hline Total ova/embryos recovered (no.) & $5.0 \pm 1.2^{\mathrm{a}}$ & $5.5 \pm 1.3^{\mathrm{ab}}$ & $7.2 \pm 1.2^{\mathrm{b}}$ & $14.0 \pm 2.3^{\mathrm{c}}$ & $<0.01$ \\
\hline Recovery (\%) & $37.1 \pm 6.2$ & $36.4 \pm 6.0$ & $42.3 \pm 6.2$ & $54.4 \pm 8.1$ & 0.39 \\
\hline Transferable embryos (no.) & $3.1 \pm 0.8^{\mathrm{a}}$ & $3.8 \pm 1.2^{\mathrm{a}}$ & $4.4 \pm 1.1^{\mathrm{ab}}$ & $7.2 \pm 1.4^{\mathrm{b}}$ & 0.05 \\
\hline Transferable/total (\%) & $60.6 \pm 9.5$ & $61.7 \pm 9.4$ & $56.9 \pm 9.3$ & $57.6 \pm 7.7$ & 0.99 \\
\hline Transferable/fertilized (\%) & $68.2 \pm 9.2$ & $86.7 \pm 7.8$ & $65.6 \pm 9.5$ & $72.6 \pm 7.1$ & 0.39 \\
\hline Freezable embryos (no.) & $2.9 \pm 0.8^{\mathrm{a}}$ & $3.7 \pm 1.2^{\mathrm{a}}$ & $3.9 \pm 1.1^{\mathrm{ab}}$ & $6.6 \pm 1.2^{\mathrm{b}}$ & 0.06 \\
\hline Freezable/total (\%) & $56.7 \pm 9.3$ & $60.1 \pm 9.1$ & $50.3 \pm 9.2$ & $54.9 \pm 7.8$ & 0.95 \\
\hline
\end{tabular}

${ }^{\mathrm{a}-\mathrm{c} W}$ ithin each row, endpoints with different superscripts are different $(P<0.05)$.

${ }^{1} \mathrm{AMH}$ quartiles: $\mathrm{Q} 1=0.01$ to $82.6 \mathrm{pg} / \mathrm{mL} ; \mathrm{Q} 2=91.1$ to $132.5 \mathrm{pg} / \mathrm{mL} ; \mathrm{Q} 3=135.3$ to $183.8 \mathrm{pg} / \mathrm{mL} ; \mathrm{Q} 4=184.4$ to $374.3 \mathrm{pg} / \mathrm{mL}$.

tral follicle count (Ireland et al., 2007), cows with high follicle numbers also had increased oocytes/embryos recovered and number of transferable embryos; however, the percentage of structures that were transferable was reduced (50.7 vs. $79.8 \%$ ) in cows with high antral follicle counts compared with cows with low antral counts. In the present study, we found no indication of a similar detrimental effect of high antral follicle count, as pre- dicted by AMH concentration, or increased superovulatory response on embryo quality, perhaps because of the optimized superovulatory protocol that was used in this study. Future studies are needed to achieve greater consistency between cows in superovulatory response, embryo collection, and embryo quality in cows with either high or low antral follicle numbers. Consideration should be given in future experiments to altering the

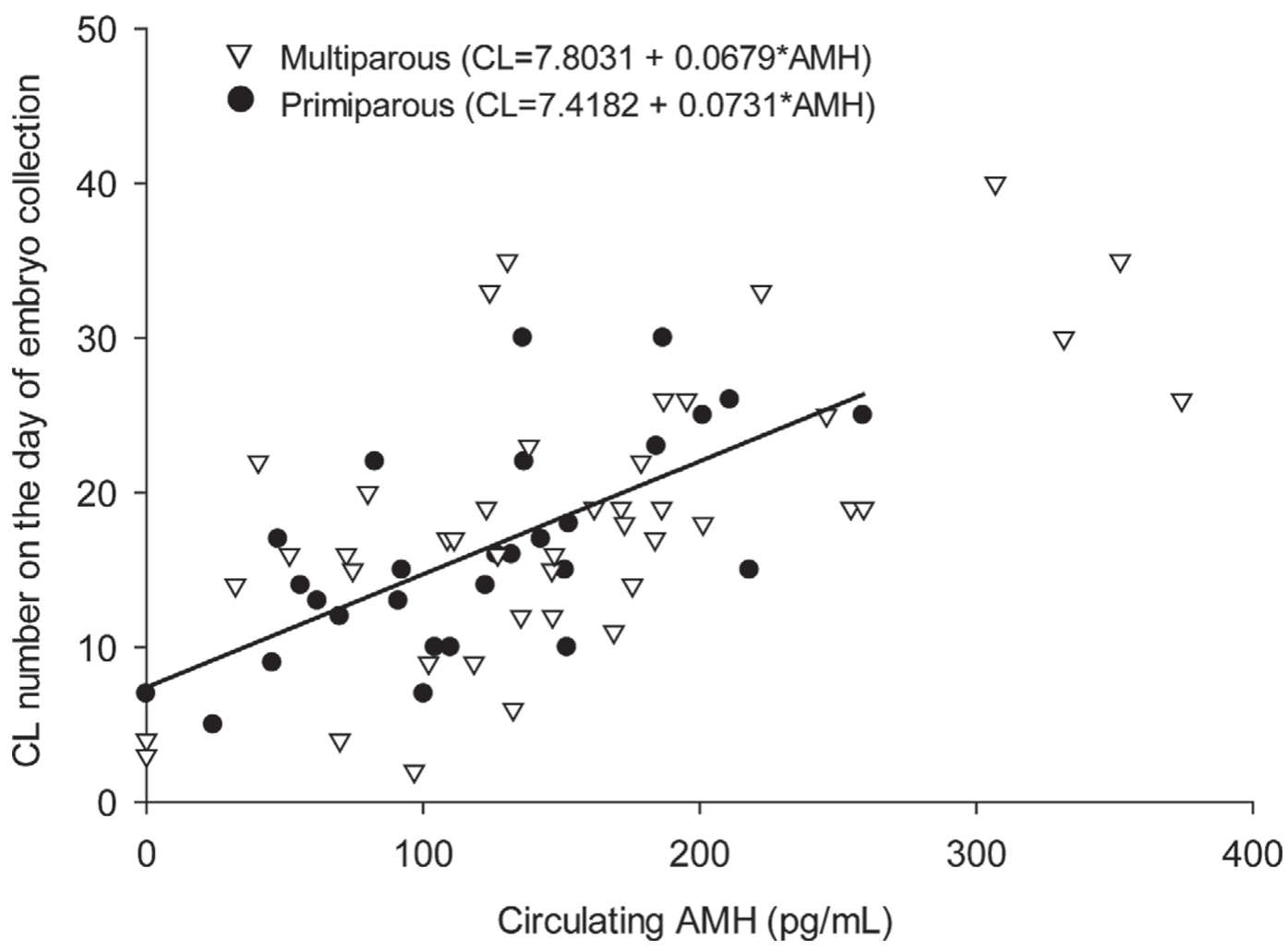

Figure 3. Average circulating anti-Müllerian hormone (AMH, pg/mL) and number of corpus luteum (CL) structures on the day of embryo collection for primiparous and multiparous cows. 


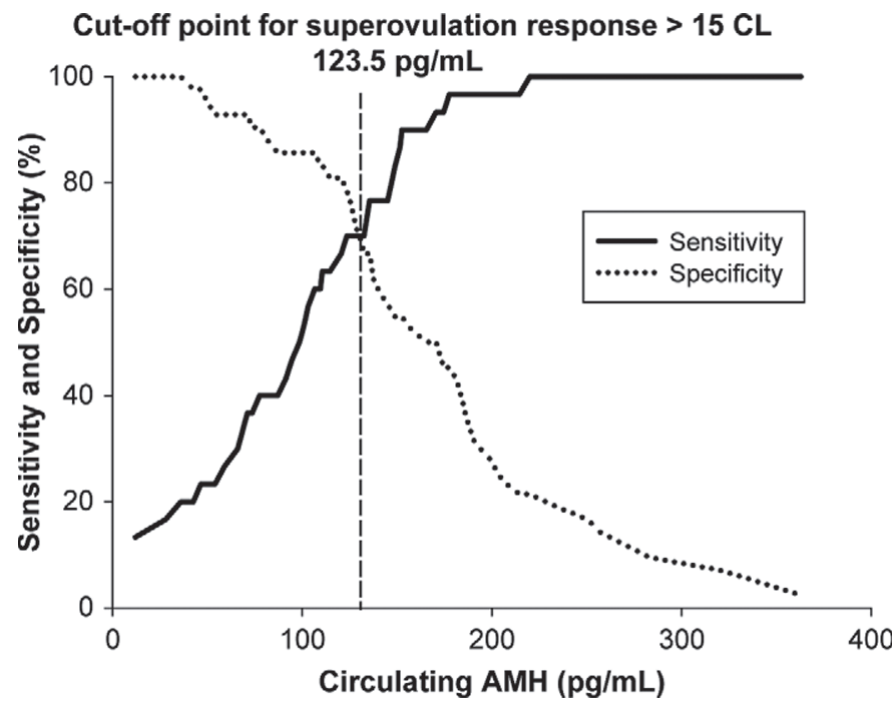

Figure 4. Estimated cut-off point for cows that had more than 15 corpora lutea (CL) in response to the superovulation, based on sensitivity and specificity of circulating anti-Müllerian hormone $\mathrm{AMH}$, $\mathrm{pg} / \mathrm{mL})$.

dose of FSH in cows with different circulating AMH concentrations. In women with polycystic ovarian syndrome, increased circulating $\mathrm{AMH}$ concentrations were predictive of a requirement for increased doses of recombinant FSH to induce development of a single ovulatory follicle (Köninger et al., 2014).

Changes in sensitivity to FSH remain somewhat controversial because of some apparent differences when comparing studies that were done with granulosa cells from different species. Bovine granulosa cells from cows with low antral follicle counts were less sensitive to $\mathrm{FSH}$, in terms of FSH induction of in vitro estradiol production and CYP19A1 mRNA expression, compared with granulosa cells from cows with high antral follicle counts (Scheetz et al., 2012). This may be due to expression of lower FSH-receptor mRNA in granulosa cells from cows with low versus high antral follicle counts (Scheetz et al., 2012). In addition, cows with low antral follicle counts have elevated circulating FSH concentrations, which could downregulate follicular FSH sensitivity to exogenous FSH stimulation (Ireland et al., 2011). In contrast, in other animal models, sensitivity to FSH was generally decreased by AMH. For example, groundbreaking research using a mouse model showed that AMH inhibited FSH-stimulated growth of preantral follicles either during in vitro follicle culture experiments or during in vivo experiments using AMH-deficient females (Durlinger et al., 2001). Anti-Müllerian hormone has also been shown to suppress primordial follicle activation in multiple species (Durlinger et al., 1999; Gigli et al., 2005). In cultured granulosa cells from species other than bovine, AMH treatment suppressed FSH sensitivity, as measured by gonadotropin-stimulated estradiol production and $C Y$ P19A1 mRNA expression (Pellatt et al., 2011; Visser and Themmen, 2014). This might be due to an AMHinduced reduction in FSH-receptor expression (Pellatt et al., 2011). Thus, results on FSH sensitivity in other species seem to differ from results observed in bovine granulosa cells, although direct comparisons between species have not yet been performed. Our observation of reduced superovulatory response in cows with low AMH might be explained in part by reduced sensitivity to FSH in these cows; however, in our opinion, the most important explanation for the observed decrease in superovulatory response in cows with low AMH remains the reduced numbers of antral follicles that can respond to the exogenous FSH treatment.

Regardless of the underlying mechanisms linking $\mathrm{AMH}$ and superovulatory response, a simple method to increase superovulatory response is to select cows that have high AMH, such as those found in the fourth quartile in our study. For example, the 18 cows in the fourth quartile produced more than twice as many CL $(213 \%)$ in response to superovulation (Q4 $=25.6$ vs. $\mathrm{Q} 1=12.0$; average per cow) and $232 \%$ more transferable embryos (Q4 = 130 vs. Q1 = 56; total for quartile) than cows in the first quartile. Thus, using the same costs of housing, feeding, FSH, and labor, the expenses per embryo would be less than half for embryos produced from cows in Q4 than Q1. In addition, all cows in Q4 had more than 15 luteal structures on the day of the flush, and nearly $70 \%(12 / 18)$ of Q4 cows had 25 or more CL. In contrast, $60 \%$ of cows in Q1 had fewer than 15 CL and none (0/18) had more than 22 CL. Thus, AMH could be used strategically by embryo transfer practitioners to reliably select donor cows with high superovulatory capacity and thus dramatically reduce costs of embryo production.

One intriguing, although weak, relationship found in these data was between BW loss from calving until embryo collection and the circulating AMH concentrations $(\mathrm{r}=-0.22)$. We evaluated BW weekly to determine the relationship between changes in BW during the early postpartum period and embryo production. A separate, in-depth analysis of these relationships is provided in another paper (Carvalho et al., 2014) and, not surprisingly, shows that cows with greater BW loss had a greater percentage of embryos that were degenerate $(46.9 \%)$ than cows that were gaining BW (9.6\%). More unexpected was the observation that differential BW change (between individuals) appeared to alter circulating AMH concentrations. Consistent with this idea is the observation that AMH decreased during the postpartum period in a group of dairy cattle that appeared to be losing substantial BW during the early 
postpartum period, based on the increase in circulating NEFA concentrations (Monniaux et al., 2013). The cows in our study had much lower loss of BW (and body condition) than cows in that study, with one-fourth of the cows in our study gaining BW (Carvalho et al., 2014). Early antral follicles are the primary source of circulating AMH (Monniaux et al., 2012) and therefore the decrease in AMH may reflect reduced antral follicle numbers in cows with greater BW loss. Although the population of early antral follicles was not measured in the current trial, an earlier study reported that increased negative energy balance (NEB) in the postpartum period reduced the follicular population in the ovaries of postpartum lactating cows (Kendrick et al., 1999). In that study, Kendrick et al. (1999) randomized cows to receive lower or higher energy diets during the first $100 \mathrm{~d}$ postpartum and reported that cows with more severe NEB had fewer early antral follicles at weekly ultrasound exams, which was confirmed by fewer oocytes being retrieved after follicular aspiration. In women, a relationship may also exist between AMH and body mass index or BW. For example, a recent study found that circulating $\mathrm{AMH}$ in women could be manipulated through energy restriction (Nybacka et al., 2013) or exercise (Moran et al., 2011). However, an earlier study that followed women that were losing BW over a period of $20 \mathrm{wk}$ failed to detect any changes in circulating AMH due to NEB (Thomson et al., 2009). Taken together, more robust testing is needed to determine the potential direct effects of NEB on circulating AMH. The cow might be a good animal model for testing this important concept that may have implications for both human and bovine reproduction.

In conclusion, circulating AMH was highly associated with superovulatory response and embryo production potential of individual cows. The repeatability and utility of the AMH assay could make it a valuable practical method for improving efficiency of multiple-ovulation embryo transfer programs in dairy herds.

\section{ACKNOWLEDGMENTS}

We thank Jerry N. Guenther (Department of Dairy Science, University of Wisconsin, Madison) and all the staff at US Dairy Forage Research Center (Prairie du Sac, WI) for their support and guidance throughout the project. This research was supported by Adisseo (Alpharetta, GA), Accelerated Genetics (Baraboo, WI), MofA Global (Verona, WI), and USDA Grant 2010-85122-20612.

\section{REFERENCES}

Batista, E. O. S., G. G. Macedo, R. V. Sala, M. D. D. V. Ortolan, M. F. Sá Filho, T. A. Del Valle, E. F. Jesus, R. N. V. R. Lopes, F. P.
Rennó, and P. S. Baruselli. 2014. Plasma anti-Mullerian hormone as a predictor of ovarian antral follicular population in Bos indicus (Nelore) and Bos taurus (Holstein) heifers. Reprod. Domest. Anim. In press.

Bergfelt, D. R., G. A. Bo, R. J. Mapletoft, and G. P. Adams. 1997. Superovulatory response following ablation-induced follicular wave emergence at random stages of the oestrous cycle in cattle. Anim. Reprod. Sci. 49:1-12.

Bergfelt, D. R., K. C. Lightfoot, and G. P. Adams. 1994. Ovarian synchronization following ultrasound-guided transvaginal follicle ablation in heifer. Theriogenology 42:895-907.

Bó, G. A., P. S. Baruselli, D. Moreno, L. Cutaia, M. Caccia, R. Tribulo, H. Tribulo, and R. J. Mapletoft. 2002. The control of follicular wave development for self-appointed embryo transfer programs in cattle. Theriogenology 57:53-72.

Bó, G. A., and R. J. Mapletoft. 2014. Historical perspectives and recent research on superovulation in cattle. Theriogenology 81:38-48.

Boni, R., M. W. M. Roelofsen, M. C. Pieterse, J. Kogut, and T. A. M. Kruip. 1997. Follicular dynamics, repeatability and predictability of follicular recruitment in cows undergoing repeated follicular puncture. Theriogenology 48:277-289.

Broekmans, F. J., J. Kwee, D. J. Hendriks, B. W. Mol, and C. B. Lambalk. 2006. A systematic review of tests predicting ovarian reserve and IVF outcome. Hum. Reprod. Update 12:685-718.

Burns, D. S., F. Jimenez-Krassel, J. L. Ireland, P. G. Knight, and J. J. Ireland. 2005. Numbers of antral follicles during follicular waves in cattle: Evidence for high variation among animals, very high repeatability in individuals, and an inverse association with serum follicle-stimulating hormone concentrations. Biol. Reprod. 73:54-62.

Carvalho, P. D., A. H. Souza, M. C. Amundson, K. S. Hackbart, M. J. Fuenzalida, M. M. Herlihy, H. Ayres, A. R. Dresch, L. M. Vieira, J. G. Guenther, R. R. Grummer, P. M. Fricke, R. D. Shaver, and M. C. Wiltbank. 2014. Relationships between fertility and postpartum changes in body condition and body weight in lactating dairy cows. J. Dairy Sci. 97:3666-3683.

Cushman, R. A., M. F. Allan, L. A. Kuehn, W. M. Snelling, A. S. Cupp, and H. C. Freetly. 2009. Evaluation of antral follicle count and ovarian morphology in crossbred beef cows: Investigation of influence of stage of the estrous cycle, age, and birth weight. J. Anim. Sci. 87:1971-1980.

Durlinger, A. L., M. J. Gruijters, P. Kramer, B. Karels, T. R. Kumar, M. M. Matzuk, U. M. Rose, F. H. deJong, J. T. Uilenbroek, J. A. Grootegoed, and A. P. Themmen. 2001. Anti-Mullerian hormone attenuates the effects of FSH on follicle development in the mouse ovary. Endocrinology 142:4891-4899.

Durlinger, A. L. L., M. J. G. Gruijters, P. Kramer, B. Karels, H. A. Ingraham, M. W. Nachtigal, J. T. J. Uilenbroek, J. A. Grootegoed, and A. P. N. Themmen. 2002. Anti-Mullerian hormone inhibits initiation of primordial follicle growth in the mouse ovary. Endocrinology 143:1076-1084.

Durlinger, A. L. L., P. Kramer, B. Karels, F. H. de Jong, J. T. J. Uilenbroek, J. A. Grootegoed, and A. P. N. Themmen. 1999. Control of primordial follicle recruitment by anti-mullerian hormone in the mouse ovary. Endocrinology 140:5789-5796.

Fanchin, R., L. M. Schonauer, C. Righini, J. Guibourdenche, R. Frydman, and J. Taieb. 2003. Serum anti-Mullerian hormone is more strongly related to ovarian follicular status than serum inhibin B, estradiol, FSH and LH on day 3. Hum. Reprod. 18:323-327.

Garbarino, E. J., J. A. Hernandez, J. K. Shearer, C. A. Risco, and W. W. Thatcher. 2004. Effect of lameness on ovarian activity in postpartum Holstein cows. J. Dairy Sci. 87:4123-4131.

Gigli, I., R. A. Cushman, C. M. Wahl, and J. E. Fortune. 2005. Evidence for a role for anti-Mullerian hormone in the suppression of follicle activation in mouse ovaries and bovine ovarian cortex grafted beneath the chick chorioallantoic membrane. Mol. Reprod. Dev. 71:480-488.

Hasler, J. F. 2014. Forty years of embryo transfer in cattle: A review focusing on the journal Theriogenology, the growth of the industry in North America, and personal reminisces. Theriogenology $81: 152-169$. 
Hehenkamp, W. J., C. W. Looman, A. P. Themmen, F. H. de Jong, E. Te Velde, and F. J. Broekmans. 2006. Anti-Müllerian hormone levels in the spontaneous menstrual cycle do not show substantial fluctuation. J. Clin. Endocrinol. Metab. 91:4057-4063.

Hirayama, H., S. Kageyama, A. Naito, S. Fukuda, T. Fujii, and A. Minamihashi. 2012. Prediction of superovulatory response in Japanese Black cattle using ultrasound, plasma anti-Mullerian hormone concentrations and polymorphism in the ionotropic glutamate receptor AMPA1/GRIA1. J. Reprod. Dev. 58:380-383.

IETS (International Embryo Transfer Society). 2010. Manual of the International Embryo Transfer Society: A Procedural Guide and General Information for the Use of Embryo Transfer Technology Emphasizing Sanitary Precautions. 4th ed. D. A. Stringfellow and M. D. Givens, ed. IETS, Champaign, IL.

Ireland, J. J., G. W. Smith, D. Scheetz, F. Jimenez-Krassel, J. K. Folger, J. L. H. Ireland, F. Mossa, P. Lonergan, and A. C. O. Evans. 2011. Does size matter in females? An overview of the impact of the high variation in the ovarian reserve on ovarian function and fertility, utility of anti-Mullerian hormone as a diagnostic marker for fertility and causes of variation in the ovarian reserve in cattle. Reprod. Fertil. Dev. 23:1-14.

Ireland, J. J., F. Ward, F. Jimenez-Krassel, J. L. H. Ireland, G. W Smith, P. Lonergan, and A. C. O. Evans. 2007. Follicle numbers are highly repeatable within individual animals but are inversely correlated with FSH concentrations and the proportion of goodquality embryos after ovarian stimulation in cattle. Hum. Reprod. 22:1687-1695.

Kendrick, K. W., T. L. Bailey, A. S. Garst, A. W. Pryor, A. Ahmadzadeh, R. M. Akers, W. E. Eyestone, R. E. Pearson, and F. C. Gwazdauskas. 1999. Effects of energy balance on hormones, ovarian activity, and recovered oocytes in lactating Holstein cows using transvaginal follicular aspiration. J. Dairy Sci. 82:1731-1741.

Knight, P. G., and C. Glister. 2006. TGF-beta superfamily members and ovarian follicle development. Reproduction 132:191-206.

Köninger, A., L. Sauter, P. Edimiris, S. Kasimir-Bauer, R. Kimmig, T. Strowitzki, and B. Schmidt. 2014. Predictive markers for the FSH sensitivity of women with polycystic ovarian syndrome. Hum. Reprod. 29:518-524.

Monniaux, D., S. Barbey, C. Rico, S. Fabre, Y. Gallard, and H. Larroque. 2010. Anti-Mullerian hormone: a predictive marker of embryo production in cattle? Reprod. Fertil. Dev. 22:1083-1091.

Monniaux, D., L. Drouilhet, C. Rico, A. Estienne, P. Jarrier, J.-L Touzé, J. Sapa, F. Phocas, J. Dupont, and R. Dalbiès-Tran. 2012. Regulation of anti-Müllerian hormone production in domestic animals. Reprod. Fertil. Dev. 25:1-16.

Moran, L. J., C. L. Harrison, S. K. Hutchison, N. K. Stepto, B. J. Strauss, and H. J. Teede. 2011. Exercise decreases anti-Müllerian hormone in anovulatory overweight women with polycystic ovary syndrome - A pilot study. Horm. Metab. Res. 43:977-979.

Mossa, F., S. W. Walsh, S. T. Butler, D. P. Berry, F. Carter, P. Lonergan, G. W. Smith, J. J. Ireland, and A. C. O. Evans. 2012. Low numbers of ovarian follicles $>3 \mathrm{~mm}$ in diameter are associated with low fertility in dairy cows. J. Dairy Sci. 95:2355-2361.

Nelson, S. M. 2013. Biomarkers of ovarian response: Current and future applications. Fertil. Steril. 99:963-969.
Nybacka, Å., K. Carlström, F. Fabri, P. M. Hellström, and A. L. Hirschberg. 2013. Serum anti-Müllerian hormone in response to dietary management and/or physical exercise in overweight/obese women with polycystic ovary syndrome: secondary analysis of a randomized controlled trial. Fertil. Steril. 100:1096-1102.

Pellatt, L., S. Rice, N. Dilaver, A. Heshri, R. Galea, M. Brincat, K. Brown, E. R. Simpson, and H. D. Mason. 2011. Anti-Mullerian hormone reduces follicle sensitivity to follicle-stimulating hormone in human granulosa cells. Fertil. Steril. 96:1246-1251.

Rico, C., L. Drouilhet, P. Salvetti, R. Dalbies-Tran, P. Jarrier, J.-L. Touze, E. Pillet, C. Ponsart, S. Fabre, and D. Monniaux. 2012 Determination of anti-Mullerian hormone concentrations in blood as a tool to select Holstein donor cows for embryo production: From the laboratory to the farm. Reprod. Fertil. Dev. 24:932-944.

Rico, C., S. Fabre, C. Medigue, N. d. Clemente, F. Clement, M. Bontoux, J.-L. Touze, M. Dupont, E. Briant, B. Remy, J.-F. Beckers, and D. Monniaux. 2009. Anti-Mullerian hormone is an endocrine marker of ovarian gonadotropin-responsive follicles and can help to predict superovulatory responses in the cow. Biol. Reprod. 80:50-59.

Rico, C., C. Médigue, S. Fabre, P. Jarrier, M. Bontoux, F. Clément, and D. Monniaux. 2011. Regulation of anti-Müllerian hormone production in the cow: A multiscale study at endocrine, ovarian, follicular, and granulosa cell levels. Biol. Reprod. 84:560-571.

Rivera, F. A., L. G. D. Mendonca, G. Lopes, J. E. P. Santos, R V. Perez, M. Amstalden, A. Correa-Calderon, and R. C. Chebel. 2011. Reduced progesterone concentration during growth of the first follicular wave affects embryo quality but has no effect on embryo survival post transfer in lactating dairy cows. Reproduction 141:333-342.

Sartori, R., C. A. Suarez-Fernandez, R. L. Monson, J. N. Guenther, G. J. M. Rosa, and M. C. Wiltbank. 2003. Improvement in recovery of embryos/ova using a shallow uterine horn flushing technique in superovulated Holstein heifers. Theriogenology 60:1319-1330.

SAS Institute. 2011. SAS User's Guide: Statistics. SAS Institute Inc. Cary, NC.

Scheetz, D., J. K. Folger, G. W. Smith, and J. J. Ireland. 2012. Granulosa cells are refractory to FSH action in individuals with a low antral follicle count. Reprod. Fertil. Dev. 24:327-336.

Singh, J., M. Domínguez, R. Jaiswal, and G. P. Adams. 2004. A simple ultrasound test to predict the superstimulatory response in cattle. Theriogenology 62:227-243.

Thomson, R. L., J. D. Buckley, L. J. Moran, M. Noakes, P. M. Clifton, R. J. Norman, and G. D. Brinkworth. 2009. The effect of weight loss on anti-Müllerian hormone levels in overweight and obese women with polycystic ovary syndrome and reproductive impairment. Hum. Reprod. 24:1976-1981.

Toner, J. P., and D. B. Seifer. 2013. Why we may abandon basal follicle-stimulating hormone testing: a sea change in determining ovarian reserve using antimullerian hormone. Fertil. Steril. 99:1825-1830.

Visser, J. A., and A. P. N. Themmen. 2014. Role of anti-Mullerian hormone and bone morphogenetic proteins in the regulation of FSH sensitivity. Mol. Cell. Endocrinol. 382:460-465. 